\title{
Videoconferencing, Affectivity and Teaching-Learning: Analysis of Professors' Perception and Students' Feelings during Videoconferencing
}

\author{
Heloisa Paes de Barros Arruda \\ Pontifical Catholic University/PUC-SP
}

\begin{abstract}
Given the importance that classes via videoconferencing are gaining as a tool in Brazilian education, in this paper we will discuss the situations that facilitate or hinder this type of learning based on the perception of students' and professors' feelings during a class. Thus we will favor the affective realm as a source of data on the success of the class and the teaching-learning process, based on Henri Wallon's theory. Wallon (1981) [1] conceives of human beings and their psychic lives in an integrated manner and cites four functional domains: affectivity, which concerns reactions of pleasure and displeasure; motor, which refers to muscle tone for moving in space; cognitive, which encompasses all intellectual functions; and the person, which ensures functional integration. Each one of them has its structural and functional identity and is, at the same time, a constitutional part of the others, making up the human being. We have chosen affectivity as the object of investigation because we feel it is an aspect that cannot be ignored in teaching assisted by audiovisual technology, since it exercises considerable influence on it, as demonstrated by the research, and thus becomes an important source of data. The results point to technical, didactic, and mediational characteristics for professors' planning in giving classes via videoconferencing, as well as indicators for the design of distance courses and selection of tools.
\end{abstract}

\section{Introduction}

The challenge of providing high-quality, free, secular education for the entire population of Brazil is an enormous one. According to the 2009 national census (PNAD-Pesquisa Nacional por Amostra de Domicílios), $9.7 \%$ of Brazilians are still illiterate [2].The Brazilian Educational Development Index (BEDI) released in the same year shows an indicator of 3.6 for Secondary Education in Brazil, when the ideal would be 6 , which is the average for OECD (Organization for Economic Co-operation and
Development) countries. Faced with this index, the Brazilian Ministry of Education has established a goal for Secondary Education to be achieved by 2028, when the BEDI should be equal to 6.0 [3]. Within this current scenario, the potential of technological resources to meet the challenges that remain has been increasingly recognized. Distance Learning has shown itself to be an important mode of education in democratizing access to schools; that is why we feel it is so important, within the broad spectrum encompassed by this field, to discuss the aspect of affectivity in the media-assisted teachinglearning process via videoconferencing. We intend to share our reflections on this investigation in this paper since we consider affectivity to be a meaningful factor in learning via videoconferencing, and that it acquires specific configurations within it, different from those of the classroom. We will set out below some considerations on the subject for specialists that design courses and select the technological resources for the curricular components.

\section{Contextualizing videoconferencing within the history of Distance Learning in Brazil}

We will adopt as our definition of Distance Learning (DL) the one established in the decree approved in 2005 by Brazil's Ministry of Education (MEC): "an educational mode in which the didacticpedagogical mediation in the processes of teaching and learning occurs with the use of information and communication technology and media, with students and teachers carrying out educational activities in separate places or at different times." Decree 5622, of December 19, 2005.

According to Cruz (2001), throughout the course of the development of DL in Brazil there have been four generations [4]. The first emerged in the 1930's, with correspondence courses and telecourses broadcast on commercial television and radio 
networks that were supported by printed materials sold at newsstands. These types of DL offered little interactivity. In the second generation, in the mid1960 's, the transmission of telecourses still occurred via commercial networks, but students attended at locations that offered face-to-face tutoring assistance. In the third generation, which extends from the 1990's onward, teaching began to benefit from the Internet for broadcasting, interaction, and the exchange of information between students and teachers in asynchronous activities through virtual learning environments, or even forming learning communities.

The author situates the emergence of videoconferencing - which allowed real-time (synchronous) interactivity of images, sound, and data - in an intermediate phase between the third and fourth generation, at the end of the 1990's. The fourth generation will fully emerge when students have greater autonomy in controlling their study time, place, and pace. According to Bôas and Portela [5], the Department of Education of the state of Bahia currently uses a videoconferencing system with six generating studios and 40 auditoriums spread over the state's 31 cities, with the capacity to reach 1,300 students simultaneously. This system can also be used in interconnection with a virtual learning environment. "In addition to meeting training demands, the videoconferencing system offers greater efficiency of management, through ease and speed of communication, and a reduction in the costs involved in technical training of government employees spread among the schools and Regional Educational Directorates" [6]. The state of Bahia, located in the northeastern region of Brazil, ranks fifth in terms of territory among Brazilian states, with 564,830 square kilometers, a population of 14,016,906 inhabitants, and an illiteracy rate of $16.6 \%$ among young people aged 15 or over [7]. The videoconferencing system, which is very similar to a face-to-face classroom situation, is an important tool for democratizing education in this state, which still had a BEDI-Brazilian Educational Development Index of 3.0 for secondary education in 2011 [8]. The State of São Paulo, on the other hand, which had a BEDI of 3.9 for secondary education in 2011 - i.e., higher than the national index of 3.4 - is the most densely populated state in Brazil with a population of 41,262,199 and an illiteracy rate of $4.3 \%$ among youths 15 years old and older [9], and has had an extensive videoconferencing structure since 2003. And since 2008 it has had streaming technology connecting the five thousand schools in the state. Thus, "it optimizes integration with the schools, enables the use of new resources, and supports management and collaborative activities in addition to significantly expanding the reach of training efforts, which are brought to educators at their own workplaces." [10]. Although not yet equipped with streaming technology, these generating studios were the context for the Arruda study [11] reported in this paper.

According to Almeida, "The advent of information and communication technologies (ICT) revived DL practices due to their flexibility in terms of time, the breakdown of spatial barriers, and the instantaneous sending and receiving of materials, which enable not only the traditional, mechanistic ways of transmitting content, now digitalized and hypermediated, but also exploit the interactivity potential of ICT and carry out activities at a distance based on interaction and the production of knowledge." (p. 330). [12]

Technology can aid not only in motivating students, but also in improving and diversifying pedagogical models [13], multiplying teaching strategies and expanding repertoires in the learning process, which would provide a more solid education. In the case of problems involving secondary education in Brazil, technological resources could contribute with proposals for new teaching models that are more attractive and effective for adolescents, which would reduce th e time required to achieve the goal of an indicator of 6 .

"In fact, technology is humanity densified; its construction is the result of a long historical series of events in the world of work. Technology being human work condensed, it belongs to everyone. The fight to reclaim it is a broad space for educational policies." [14]

However, the bets made on technology do not achieve results unless there is a change that encompasses all of educational digital culture, from curricula through the education and practices of docents and supervisors. Affectivity would be one of the dimensions to be considered in building this new digitalized educational culture. Students learn through the relationships they establish with docents, with fellow students, with knowledge and with technological artifacts - all of these are part of their milieu, and their development results from all these interactions. "We are privileged components of our student's milieu. To make it more favorable to development is our responsibility." [15]

\section{Affectivity according to Henri Wallon}

Wallon [1] conceives of human beings and their psychic lives in an integrated manner and cites four functional domains: affectivity, which concerns reactions of pleasure and displeasure; motor, which refers to muscle tone for moving in space and is the basis of attitude; cognitive, which encompasses all intellectual functions; and the person, which ensures functional integration. Each one of them has its structural and functional identity and is, at the same time, a constitutional part of the others, making up the human being. 
Since our interest is in investigating affectivity in the teaching-learning processes via videoconferencing, we shall focus the description on this aspect. Affectivity is the ability of a subject to be affected positively or negatively by the world inside and outside him/her, responding to each situation experienced with pleasure (feeling good) or displeasure (feeling bad). Thus, affectivity, when it predominates, is the energy that mobilizes a person to act, giving direction to the cognitive and motor aspects; therefore, it is one of the important aspects in mobilizing students' attention in a teachinglearning situation and demands special care in the case of videoconferencing, inasmuch as it is a situation where the protagonists see each other (not simultaneously as they speak, but sequentially, when the image passes to the other pole), which allows for the perception of affective reactions.

Affectivity, in an evolutionary process, moves through three successive moments: emotion, feelings, and passion.

Emotion is organic and, depending upon its intensity, has the power to shake the psychic-organic system from end to end; it is the exteriorization of affectivity and has as its base muscle tone, which is what enables the body to communicate, constituting what Wallon calls plasticity. Another important characteristic of emotion is its power to mobilize similar or opposite reactions in others, referred to as contagion.

"Emotion establishes an immediate relationship between individuals, independently of the whole intellectual relationship." [16] This immediate relationship can also be established by means of videoconferencing, since it is a technology that allows participants to see each other in real time (synchronously), observing the plasticity of bodies that communicates and elicits feelings. Other information and communication technologies used in Distance Learning offer less opportunity for such immediate relationships.

Feelings are part of a more elaborate stage of affectivity, preponderantly cognitive, and require an abstraction/representation; they are generally accompanied by emotion, but the intellectual activity inherent in feelings is capable of reducing the power of emotion. When we bring emotion into consciousness and represent it, naming it, it is reduced.

The final component of affectivity, passion, has as the author defines it a character very different from that commonly understood. According to Wallon, the cognitive is preponderant in passion, to the point of silencing emotion, because it implies self-control over it. It appears only after the age of three, it is more hidden, more lasting, and more focused.

Reactions of pleasure and displeasure that reveal the subject's values, interests, urges, needs, and motivations therefore belong to the realm of affectivity.

The affective, motor, and cognitive domains feed on each other and may, in various situations, function with the predominance of one over the other, but the three are always present. Often teachers in the various fields of knowledge focus only on the cognitive domain and give little or no attention to affective and motor aspects. There are many reasons why this happens: pressure to deliver the scheduled content, poor working conditions, little sharing of experiences with colleagues, lack of support from the principal and coordinators, weaknesses in initial or continuing education, lack of time to prepare - and constantly re-prepare - an effective class plan, among other factors. It is essential that initial and continuing education consider a more integrated view of the individual, appropriately preparing professionals for the art of educating.

\section{Student affectivity during videoconferencing}

Videoconferencing was born within the corporate context to enable business meetings among professionals in distant locations. In recent decades, as a result of its potential, it began being used in education. In the case of Brazil, a country that is territorially vast, it enables renowned specialists in education to give classes to a large number of students spread over cities in different states, reaching even cities that are less accessible.

Based on the results of qualitative research [11], we will describe below some feelings and emotions perceived by three female students (referred to as A1, A2, and A3) during a videoconference class, and we shall discuss their implications for the teachinglearning process. The students are teachers that work in elementary education and that were at that time doing an in-class continuing education course strongly supported by interactive technologies (University Level Continuing Education Program for Cities), with a 2-year duration. [17] This teaching certification course, which certified 4,700 teachers located in 41 cities in the state of São Paulo, included media-assisted activities via videoconferencing, teleconferencing, and those in virtual learning environments.

The videoconferencing model used by the Continuing Education Program-University Education for Cities program is a multi-point one, in which a room, called a generating studio, connects by telephone line with five centers spread throughout the state of São Paulo, each one with 40 students, a tutor, and a technician. The generating studios are rooms measuring from 10 to $12 \mathrm{~m} 2$ with acoustical treatments, air conditioning, and videoconferencing equipment: a 33-inch television, a documentary 
camera, VCR, multimedia computer, mediaintegrating podium, sound system, and desk microphone. The videoconferencing professor sees images from the centers only when s/he grants them speech and image access, and can see only one center at a time. $\mathrm{S} / \mathrm{he}$ can opt to participate in pedagogical-technical training before giving classes via videoconferencing. The centers are equipped with tables and chairs for 40 students, two television sets - one with a 33-inch screen and the other a 29inch screen, videoconferencing equipment, a camera, two handheld or desk-type microphones, speakers, a documentary camera, a VCR, and a multimedia computer.

The videoconferences took place twice a week, with a duration of three hours each and a 20-minute break. In the case of the course under study, 135 videoconferencing professors gave 1,157 videoconferences (numbers refer to Pontifical Catholic University of São Paulo, one of two universities responsible for running the course).

Based on accounts that students gave of the feelings they perceived in themselves, it was possible to list situations that hinder the media-assisted teaching and learning process via videoconferencing:

a) Projection of a film that was poor in terms of technical quality. Student A2 identified the feeling of dissatisfaction in the situation where the projection of a film with poor technical quality and muffled sound were a hindrance to proper reflection.

b) The posture and expression of the videoconference presenter while waiting for students to do the exercises. Embarrassment was a feeling noted by A1 when watching the posture and expression of the videoconference presenter in the above-mentioned situation. Another situation that triggered this feeling was the fact that the professor was waiting for responses that were not forthcoming: "another thing that embarrassed me [was] because he kept waiting for people's responses." A1 also named the feeling of embarrassment felt by the videoconferencing professor while he waited for students to ask questions. So, contagion occurred with this student: she felt embarrassed when she noted the professor's embarrassment, which hindered her participation in the class.

According to Wallon, "Emotion needs to elicit similar or reciprocal reactions in someone else and, inversely, has a great power of contagion over others. It is hard to be indifferent to its manifestations, not to join oneself to them through raptures in the same direction, whether complementary or even antagonistic." (p. 99). [16]

c) Unvarying tone of voice. An unvarying tone of voice makes one sleepy and causes students to stop paying attention. A1 perceives in herself a feeling of discomfort in this situation. Modulation of the voice, as well as body tone, can also provoke reactions of pleasure or displeasure, can communicate to others how the person is being affected, causing feelings. Thus, the tone of the professor's voice, the intonation when speaking, diction, or loud and muffled sound interfere in students' attention during a class via multi-point videoconferencing from a generating studio.

However, the same student also perceives the teacher as affectionate: "I think that the way he talks, his manner... he must be the hugging type, he gives the impression of being affectionate."

d) Non-participation of students. A fact that consequently interferes in dialog and interaction with the professor elicited feelings of discomfort and guilt. According to A1, the objective of videoconferencing is for them to speak, and she acknowledged the aforementioned feelings in this situation. She stated, "There must be interactivity, if there isn't, it won't work. There needs to be dialog between the videoconference presenter and the people on this side." A1 noted that she is shy and finds it hard to participate in classes via videoconferencing, due to the need to speak into the microphone and be seen on the circuit going to the other four locations, in addition to the generating studio, where the professor is located.

Emotion, depending upon its intensity, has the power to make intellectual activity subside, prevailing over the cognitive.

Student A1 suggests that the professor employ various capabilities in communicating: "it has to be a person that with a look, with the spoken word, with gestures, with the tone of voice, I think there are various elements, all of them." And using them encourages and challenges the student. She is referring, then, to communicating emotion and feelings by means of expression.

e) Intense repetition of explanations of content. Student A3 perceives feelings of dissatisfaction and boredom due to the intense repetition of explanations of content to resolve the doubts of colleagues from different centers. In a distance class in which 200 students participate, it is complicated for the teacher to manage everyone's doubts. In this case, the videoconference presenter could establish a partnership with the tutors present in each of the five classrooms to minimize such questions on the spot. Besides the difficulty of assisting 200 students, technical problems may occur, such as sound and images breaking up at the individual centers, which could have an influence on increasing questions. Or in the case of a PowerPoint slide containing letters that are too small. As regards didactics, the way in which the videoconferencing professor imparts knowledge to students and proposes interactions and activities may not be sufficiently clear, due not only to the heterogeneity of the students but also due to a standard of language that is hard for students to understand. 
Thus, there are in this videoconferencing model points that require the attention of the specialists that develop pedagogical projects and select the technologies for more individual and personalized interventions. According to Almeida, "Each media resource employed in distance education has specific structural characteristics and possible levels of dialog based on the media itself, which interfere in the level of transactional distance. Likewise, in a classroom environment the level of dialog and participation of students is fostered by the pedagogical approach taken by the professor and the respective pedagogical strategies and mediations." (p. 334) [12]

We present below situations that facilitate the media-assisted teaching-learning process via videoconferencing:

a) Survey of previous knowledge. Students A1 and A2 acknowledged a feeling of satisfaction when the professor asked what they knew about the theoretical content addressed in the videoconference. It is important to survey previous knowledge in order to facilitate the learning process.

b) Showing of a film. This was the second situation experienced by A1 that generated satisfaction. In her opinion, it could promote discussion.

Thus we see that students' perception of their own feelings and the description of the situations that trigger them make it possible to identify what facilitates and what hinders learning. And consequently we can provide some principles for teachers in planning and mediating learning. In the interaction between students and the videoconferencing professor, affective, cognitive, and motor aspects are always present and should be taken into account even when the relationship is media-assisted using technology. Teachers and students, even when geographically separated within a technological environment of DL, express and perceive feelings and emotions in themselves and in each other. This also occurs due to the fact that this interactive media, videoconferencing, allows teachers and students to exchange images and sound in real time. In this way, classes via videoconferencing come close to the face-to-face classroom experience and make DL a new and related field of research [18].

A study carried out in 2005 (J. Hauber (et al.) [19], that had as its objective to compare the sensation of social presence in three contexts - 2-D videoconferencing, 3 -D videoconferencing, and local face-to-face communication - reported that strong social presence occurs first in the face-to-face mode, secondly in the 3-D videoconferencing mode, and thirdly in 2-D. However, for the implementation of 3-D technology, or even holographic projections, the cost is still high, despite advances in technology. In Brazil, 3-D videoconferencing exists only in research laboratories.
Cruz [20] notes further that characteristics reported in the literature on DL courses regarding problems such as solitude, feelings of abandonment, and lack of social contact with peers cannot be directed towards studies of videoconferencing. For the docent, the communication approaches the orality of face-to-face situations, but it is more open to improvisation and unpredictability than other DL tools.

\section{Affectivity of the videoconferencing professor}

On the other hand, what are the challenges faced by professors when giving classes via videoconferencing? Is it possible that a correlation exists between the situations referenced by the students and those that appear in the professors' perceptions?

Based on the statements given by videoconferencing professors (identified as P1, P2, and P3) about their own perceived feelings in the qualitative study [11], it was possible to list situations that hinder the media-assisted teaching and learning process via videoconferencing:

a) Management of the time and content planned for the videoconference. P1 noted concern with the need to finish the topic being worked on within the prescribed timeframe, since he was aware that he "couldn't go so quickly that students would feel they were being run over."

b) Meeting the needs of all the students. P2 felt concern with the need to meet the needs of all students, wanting to be able interact, to aid comprehension, and meet the objectives of her class, which is difficult on a circuit with 200 students connected via videoconferencing.

c) Students' lack of attention during the videoconference. P2 perceived her own sense of frustration, explained as "getting an icy feeling", an expression that indicates a more intense and fleeting, emotional bodily reaction, reflecting a sensation of coldness. Not all students perceive your excitement, dedication, and effort during the videoconference. There are some learning centers that are totally tuned out when she plays back the tape, the students seem distracted, are doing other things, reading the teaching materials, not paying attention to the videoconference, while she is in the generating studio feeling impassioned and making her best effort. She feels impotent in this situation. There seems to be no relationship between the videoconferencing professor and the students at the center; at this point in time there is a split in the

teacher-student dialectical pair [16]. The feeling of presence provided by videoconferencing, which approximates that of a classroom situation, appears to diminish in this context of 200 students. P2 states also that there are many students and it is hard to 
give them all attention, which may be a cause of the distraction. She stated: "when they note that I have come into the center, there is an interruption, even if they keep talking. It's as though they feel they are being watched, because I am there in the room." So, when the students are shown on the television to all the circuit, they feel they are being watched.

d) Little student involvement in the exercises, which provokes the feeling of frustration reported by P1. According to S1, student non-participation during the videoconference makes her feel uncomfortable and guilty.

e) Expectation and waiting for students to do the exercise. P1 feels anxious and uncomfortable, and says he keeps a poker face while waiting for the students to do the exercises. According to P1, "there is a feeling of expectation and an emotional stirring on my part that is very different from a classroom situation. One of the reasons may be related to this professor's meager experience in giving classes via videoconferencing. Waiting for something and you don't know exactly what is happening." He says he needs to learn to handle this way of teaching, as he once learned to handle classroom teaching. "Maybe if I do it more often, there will be a time when I invent something to relax, to have an attitude that favors learning." (P1) This anguish and muscular tension during the wait is described by Wallon [16],"Any wait is accompanied by a state of muscular tension that increases as the wait continues and may turn into anguish" (p. 131). According to $\mathrm{P} 1$, it is at this point that VC presents a limit on interaction with students during an exercise: "you make a proposal and have no way to interact," which he says causes anguish. In this same situation, A1 noted this feeling in the professor and felt embarrassment. A videoconferencing professor's tense posture does not aid the teaching-learning process.

f) Mandatory repetition to see if they have understood the activity. According to P2, "you give them an activity and you go from learning center to learning center to see if they have understood." The professor's justification for doing this is due to the students' lack of attention, which is the reason for the repetition. And which in S3 caused boredom and dissatisfaction.

g) At the end of the videoconference, professors P1 and P2 felt relief. According to P1, he was quite tired out by all the technological apparatus to be manipulated during the $\mathrm{VC}$, which requires control of a lot of information, precision of movement in clicking correctly and handing over the floor to a center or running a portion of a film, etc. He also cites tension in controlling the time for covering all the content in up to three hours. He claims it is a burden, it consumes a lot of the professor's energy. Which Cruz [4] also noted in his study: Fatigue on the part of professors due to the energy spent on managing the technology, added to lack of knowledge about handling that technology and the new situation of giving classes via videoconferencing.

P2 also mentions the aspect of uncertainty and lack of knowledge, since giving classes via VC is new to most professors. She mentions "the issue of feedback, which is not immediate, so you don't really know what is happening."

We present below situations that facilitate the media-assisted teaching-learning process via videoconferencing:

a) Interaction with students at the different centers. They gave feedback and two or three spoke. P1 has a feeling of satisfaction deriving from this professor-student interaction, even though they are separated geographically. This situation was also perceived by $\mathrm{P} 2$ as a feeling of pleasure: "There was an exchange, they sought me out, they questioned me." According to Cruz "The more interaction you want, the more planning you need to do." (p. 89) [20].

b) Owning of the concept by students. P3 feels satisfaction in this situation, reporting that: "the concept you are working on, it is being minimally owned."

According to Silva [21], the following aspects should be taken into account by professors in planning their classes via videoconferencing: what the objectives of the class are; what the profile of the participants is, and the knowledge they already have of the topic to be discussed; how to organize the content within the duration of the videoconference; whether the materials will be previously available to the participants; how to prepare the dynamics of the classes; how to include the aspect of affectivity; what will be the strategies for student participation; check technical issues (possibility of eliminating outside noise, quality of video and sound, as well as the professor's posture and language; care in planning the presentation of materials to also allow interaction of the participants.

Added to these recommendations are those presented by Weckelmann: The professor "being a good communicator is an aspect that distinguishes the teacher's work, since clear and quick communication can become a point of difference in a distance class." (p. 11) [22]. The author systematizes three aspects to be developed by the professors: technological knowledge, incorporation of new ways of communicating, and management.

Nevertheless, certain difficulties noted by Arruda [11] cannot be resolved by these measures alone, since they relate to working conditions. The large number of students made it difficult to build and maintain a proximity between professor and students that would facilitate the teaching-learning process. The repetition and difficulty in being present at all centers demonstrated this, as well as the professor's 
sense of frustration and impotence, since they perceived students' lack of attention as being disproportionate to their teaching efforts. The need was also shown for specific training of the professors to perform in the audiovisual mode, something like scenic-media training that would enable them to find solutions for their own difficulties with this longdistance, media-assisted audiovisual technology, which would not give them the feeling, for example, that they are "poker-faced." Besides the specific measures aimed at VC, like those mentioned by Weckelmann and Silva, technical precariousness and working conditions carry considerable weight in the results of the class, affecting the participants' feelings and the teaching-learning process. The worse the working conditions, the more difficult it is to transmit a satisfactory presence via videoconferencing.

\section{New perspectives}

Multicast videoconferencing was used during the year 2011 in the UCA-One Computer per Student Project, (See more about the UCA Project [23]) with a format of meetings between researchers and training teams, so that the latter could receive orientation, discuss next steps for implementation of the Project in schools, present the materials produced by the schools, and thus train the teachers in each school later on (Valente and Martins, 2012) [24]. The videoconferencing was done in four locations: the State University at Campinas/UNICAMP UCA room in Campinas-SP, with researchers doing the coordination, connected to three other rooms located in the north of Brazil, also with researchers and trainers: at UFPA-Federal University of Pará in Belém-PA; at UNIR-Federal University of Rondônia in Porto Velho-RO; and UFAC-Federal University of Acre in Rio Branco-AC. Approximately 8 to 12 people participated in these videoconferences in each location, a total of 32 to 48 people, very different from the 200 students in the context analyzed above [11]. Under the coordination of UNICAMP, there are four schools in four cities in the state of São Paulo; in Acre there are nine schools in seven cities; in Pará there are nine schools in nine cities; and in Rondônia there are nine schools in seven cities, which is an indication of the significant reach of this Project and the potential of videoconferencing.

The results presented by Valente and Martins of these videoconference training meetings were that the participants "were able to acquire know-how about how to train and operate in the schools so that the UCA Project could be implemented and the laptops could be used by the students in conjunction with curricular activities in the classroom.” (p.11) [24].

So it is important to highlight new initiatives with the use of videoconferencing for training teachers and the benefits of this mode of distance learning in vast countries such as Brazil. The advantages pointed out by Valente were "transmission of image and sound to various different points at the same time; time savings, avoiding physically moving to a single location when people are geographically dispersed; monetary savings, eliminating th e need to travel and reducing costs and time spent; and the possibility of yet another research tool, since the meeting can be recorded and made available later on." (p. 11) [24].

Another initiative involving the pioneering use of videoconferencing in Brazil occurred between 2000 and 2002, in a Masters program in Production Engineering with the participation of 31 students. According to Tavares, "It was noted in respondents' reports that despite the classes being given at a distance, the feeling of "belonging" and of "proximity" were very strong. Reinforcing the dimension of interactivity, affectivity, and collaboration among students and professors in the course, guaranteeing that in these aspects, as well as the building of knowledge, videoconferencing was considered better than face-to-face classes." (p. 6) [25]. There is an approximation of this study with Arruda's [11] as regards the aspects of affectivity and interactivity of the class via videoconferencing; however, as regards belonging, proximity, and the building of knowledge being considered better than a classroom situation, findings are divergent. So two hypotheses can be raised: the difference in the level of teaching and the number of students participating in the videoconferencing (31 and 200).

Tavares [25], on the other hand, points out challenges and obstacles that must be overcome: greater effort on the part of students and professors than in a classroom situation, expensive technology, inexperience with the equipment on the part of the students, poor image quality at times, change in the arrangement of chairs in the videoconferencing room to a U-shaped configuration, greater frequency of the orientation and evaluation system. Some of these challenges were also noted by Arruda (2005) [11]: efforts of the teachers, as reported by $\mathrm{P} 1$ and $\mathrm{P} 2$, who felt relief at the end of the videoconference; difficulties with the equipment on the part of the students, some of them being embarrassed to speak into the microphone and be seen on the circuit by 200 students; technical issues, such as muffled sound. Inexperience with the equipment on the part of the professors was also brought out.

Tavares [25] also presents some suggestions: detailed planning of content and questions and the interspersion of a variety of materials (images, films, overhead projectors, slides) during the class. In the study by Arruda [11], student S1 felt satisfaction when the professor used a film, diversifying the material used. They also pointed out the need for high quality of materials. 
This discussion on the impact of videoconferencing in education is also presented in other areas, such as neurology: the study done with an RNRBF - ICV software, which is "a system for assessing and classifying student preferences in relation to the performance of the Virtual Body Image (VBI) of the professor giving the courses via videoconferencing, using artificial neural networks with the radial basis function (RBF) technique" (Bastos, Xavier, Spanhol, 2004, p. 1) [26]. In the article, (Bastos, Xavier, Spanhol, 2004) [26] thirtytwo characteristics are described which comprise the professor's Virtual Body Image, separated into seven groups. They are the following: initial perception, movements, body parts, language, emotions, visualization, and position. We thus see corroborated in other areas of knowledge the importance of discussing the presence of feelings and emotions during the course of videoconferencing.

\section{Conclusions}

Based on analysis of the perceptions and reactions reported by the students interviewed and by the videoconferencing professors, we propose a division into three criteria that summarize the situations that trigger negative feelings (students: dissatisfaction, boredom, discomfort, guilt, embarrassment; professors: concern, frustration, anxiety, discomfort, anguish) and positive ones (satisfaction). We believe that if used in planning and in teaching mediation, the following criteria can help achieve the educational objectives of courses that use videoconferencing: a) Technical support and working conditions that ensure high-quality transmission of images and sound and that offer favorable conditions for holding the class, without an excess of demands that cannot be met or that negatively impact the class format and participants' performance, such as too many students and centers, which made it difficult to react to students' needs and be fully present and also led to excessive repetition. b) Mediation during the class: (i) good management of technological resources (films, slides, activities) in order to foster educational objectives so that they, together with the teacher's pedagogical approach, may elicit discussion and interactions; (ii) more intervention by the teacher while students are doing exercises, posing problems and interacting with students while they carry out the activity, and remaining attentive to his/her own posture and expression while waiting for student responses; (iii ) good vocal projection on the part of the videoconference presenter in order to keep students' attention during the learning process. (iv) constant interaction with students at the different centers, insofar as is possible. c) Didactic planning: (i) pay special attention to planning moments that promote interaction and dialog with students; (ii) foster group learning situations in the multi-point videoconferencing generating studio; (iii) provide for an initial survey of previous knowledge, which serves to mobilize prior understandings, valuing and engaging students, and making it possible to start from a level of knowledge agreed upon by all participants and better reach the group of 200 students. (iv) management of the time and content planned for the videoconference; and (v) propose activities that lead to students "owning" the concept. We believe that the situations of feelings perceived by the students can be extended to other desktop videoconferencing technologies, and even to more advanced equipment such as 3 -D videoconferencing, telepresence, or holographic projection. A considerable problem for the widespread use of videoconferencing in education in Brazil is the high cost of the equipment. As an alternative there are desktop videoconferences, more accessible via IP, with video in real time. These involve free software available on the Internet that allows for synchronous interaction via Internet, depending on a connection, microphones, and webcams. However, in such situations the interaction is between each person individually on his/her computer interacting with the others, which is similar to an audiovisual chat, and loses the relationship and bond among the group. The realities in Brazilian public schools, according to a 2010 report on ICT education [27], is that there are only 24 computers per school in use and operational in the public schools interviewed in the Southern region, 19 computers per school in the Southeastern region, and 13 computers per school in the Northeastern region. Desktop videoconferencing in Brazil is more often used in distance courses at the college level, in some non-degree courses, and more assiduously for teacher education, mainly in the state of São Paulo. Another issue addressed in the literature, which goes beyond technical limitations, is limited knowledge of the pedagogical potential of videoconferencing. It is our intention, following this discussion of the implications of affectivity in the learning process via videoconferencing, that specialists and docents, when conceiving the design of DL courses, consider the dimension of affectivity, especially when selecting the types of technologies that will be used in courses, regardless of the mode (DL, semi-, or face-to-face), but to achieve the educational objective. We often note, at such junctures, an excessive emphasis on content and selfinstructional materials, eclipsing other aspects of the teaching and learning process, as in the case of preparing the medium with challenging situations for the students. We emphasize as well the importance of professors being sensitive during their mediation to perceiving manifestations by students and reorganizing learning situations. 


\section{References}

[1] WALLON, H. A evolução psicológica da criança [The Psychological Development of the Child], Edições 70, Lisboa, 1981.

[2]<http://www.ibge.gov.br/home/presidencia/noticias/noti cia_visualiza.php?id_noticia $=1708>$ (Access date: 2 May 2012).

[3]<http://download.inep.gov.br/educacao_basica/portal_id eb/metodologias/Artigo_projecoes.pdf/> (Access date: 2 May 2012).

[4] CRUZ, D. M. O professor midiático: a formação docente para a educação à distancia no ambiente virtual da videoconferência. [The media-assisted professor: teacher training for distance education within the virtual environment of videoconferencing]. Doctorate in Production Engineering, Federal University of Santa Catarina, 2001.

[5] BÔAS, Vitor O. V.; PORTELA, Brino R. Soluções interativas de vídeo e videoconferência integrados ao Moodle. [Interactive video and videoconferencing solutions integrated with Moodle]. Curitiba, 13 Congresso Internacional de Educação a Distância [13th International Conference on Distance Learning], 2007, p. 1- 8.

[6] <http://www.iat.educacao.ba.gov.br/node/64> (Access date: 2 august 2012)

[7] <http://www.todospelaeducacao.org.br/educacao-nobrasil/numeros-do-brasil/dados-por-estado/bahia/> (Access date: 2 august 2012)

[8] http://ideb.inep.gov.br/resultado/

resultado/resultado.seam?cid=2600189> (Access date: 2 august 2012)

[9] <http://www.todospelaeducacao.org.br/educacao-nobrasil/numeros-do-brasil/dados-por-estado/sao-paulo/> (Access date: 2 august 2012).

[10] http://www.rededosaber.sp.gov.br/ portais/Quemsomos/Infraestrutura/tabid/185/language/ptBR/Default.aspx> (Access date: 2 august 2012).

[11] ARRUDA, H. P. B. Percepção de sentimentos e emoções na videoconferência: um estudo com alunas do PEC- Municípios [Perception of feelings and emotions in videoconferencing: a study of students in the Continuing Education Program-Cities]. Masters in Educational Psychology - Pontifical Catholic University of São Paulo São Paulo, 2005. Available at: <http://weblab.tk/sites/default/files/bibliografia/HeloisaArr uda-mestrado.pdf.> (Access date: 15 December 2011)

[12] ALMEIDA, M. E. B. Educação a distância na internet: abordagens e contribuições dos ambientes digitais de aprendizagem. [Distance education on the Internet: approaches and contributions of digital learning environments] IN Educação e Pesquisa, São Paulo, v. 29, n. 2, p. 327-340, Jul /Dec 2003, p. 327 - 340. Available at: <http://www.scielo.br/pdf/ep/v29n2/a10v29n2.pdf.> (Access date: 2 May 2012)

[13] KARSENTI, T. As Tecnologias da informação e da comunicação na pedagogia. [Information and communication technologies in pedagogy] IN TARDIF, M. \& GAUTHIER, C. A Pedagogia: Teorias e práticas da antiguidade aos nossos dias [Pedagogy: theory and practice from antiquity to the present day], Rio de Janeiro, Vozes, 2010 , p. $327-350$.

[14] ALMEIDA, F. J. Paulo Freire, Publifolha, São Paulo, 2009.

[15] MAHONEY, A. A. A constituição da pessoa: desenvolvimento e aprendizagem [The makeup of the individual: development and learning]. In: MAHONEY, A. A. and ALMEIDA, L. R. A constituição da pessoa na proposta de Henri Wallon [The makeup of the individual according to Henri Wallon], Loyola, São Paulo, 2004, pp. 13-24.

[16] WALLON, H. As origens do caráter na criança [The origins of character in children], Nova Alexandria, São Paulo, 1995

[17] <http://ls-core-02.pec.sp.gov.br/externa/index.asp> (Access date: 2 May 2012).

[18] KEEGAN, D. Distance Education Distance Education Technology for the New Millennium Compressed Video Teaching. IN ZIFF Papiere 101, 1995. Available at: <http://www.eric.ed.gov/PDFS/ED389931.pdf> (Access date: 2 May 2012)

[19] Hauber, J. (et al) Social Presence in Two- and ThreeDimensional Videoconferencing, 2005. Available at: <http://www.temple.edu/ispr/prev_conferences/proceeding s/2005/Hauber,\%20Regenbrecht,\%20Hills,\%20Cockburn, $\%$ 20Billinghurst.pdf > (Access date: 2 May 2012)

[20] CRUZ, D. Aprendizagem por videoconferência. [Learning via videoconferencing] IN Educação a Distância: o estado da arte. [Distance Education: the state of the art] LITTO, F. M. and FORMIGA, M. Pearson Education do Brasil, São Paulo, 2009, p. 87 - 94.

[21] SILVA, Siony. A videoconferência como recurso de educação a distância [Videoconferencing as a resource in distance learning]. In Sinergia, São Paulo, v. 12, n. 2, p. 158-164, maio/ago. 2011.

[22] WECKELMANN, Valéria F. O Trabalho Docente no Ambiente Virtual de Aprendizagem da Videoconferência Estúdio de Geração. [The Work of Teaching in the Virtual Learning Environment of the Videoconferencing Generation Studio] 18 Congresso Internacional de Educação a Distância [18th International Conference on Distance Learning], Santos, 2008, p. 1 - 13.

[23] <http://www.uca.gov.br/institucional> (Access date: 2 august 2012).

[24] VALENTE, José A.; MARTINS, Maria C. O Projeto UCA e a formação de professores das instituições de ensino parceiras vinculadas à UNICAMP: o uso da 
videoconferência [The UCA Project and the training of teachers from UNICAMP's partner educational institutions: the use of videoconferencing]. In: ENCONTRO NACIONAL DE DIDÁTICA E PRÁTICAS DE ENSINO, 2012, [S.1.].

[25] TAVARES, Valéria R. C. Videoconferência: uma experiência de sucesso [Videoconferencing: a successful experience]. 12 Congresso Internacional de Educação a Distância [12th International Conference on Distance Learning], Florianópolis, 2006, p. 1- 11.

[26] BASTOS, Lia C.; XAVIER, Edite; SPANHOL, Fernando. Educação a Distância: utilização de rede neural artificial na avaliação da imagem corporal virtual do professor que media cursos através de videoconferências [Distance Learning: use of an artificial neural network in assessing the virtual body image of professors giving classes using videoconferencing]. 11 Congresso Internacional de Educação a Distância [11th International Conference on Distance Learning], Salvador, 2004, p. 1 11.

[27] <http://cetic.br/tic/educacao/2010/index.htm> (Access date: 2 august 2012). 